\title{
Nuclear Segmentation, Condensation and Bilateral Symmetry in Polymorphonuclear Leukocytes Reflect Genomic Order and Favor Immunologic Function
}

\author{
Jyoti P. Chaudhuri ${ }^{\mathrm{a}, \mathrm{b}}$ Joachim U. Walther ${ }^{\mathrm{a}}$ \\ ${ }^{a}$ Genzyme Genetics, Phoenix, Ariz., USA; ${ }^{b}$ Kinderklinik, Ludwig-Maximillians-Universität, Munich, Germany
}

\section{Key Words}

Bipolarity $\cdot$ Chemotaxis $\cdot$ Cytoskeleton $\cdot$ Myeloid leukemia $\cdot$ Intranuclear order $\cdot$ Neutrophils $\cdot$ Nuclear segmentation

\begin{abstract}
Segmentation, condensation and bilateral symmetry of the nuclei of polymorphonuclear leukocytes seem related to their function. Segmentation of the nuclei into two or more lobes and their condensation facilitate their passage (diapedesis) through the endothelial layer of blood vessels to the extravasal space and subsequent locomotion through the interstitial compartment of different tissues. Bilateral symmetry of these nuclei along with their association to the cytoskeletal fibers contribute to their efficiency in locomotion by alignment of the axis of nuclear symmetry to the axis of cellular polarity, which orients towards the direction of locomotion in response to cytokines and other stimuli. Observations of the cytogenetic facets of intranuclear order support these assumptions.

Copyright $\odot 2012$ S. Karger AG, Basel
\end{abstract}

\section{Introduction}

Here we present a model of the relationship between nuclear morphology and cellular function of polymorphonuclear (PMN) leukocytes in the light of our cytogenetic observations. Segmentation, chromatin condensation and bilateral symmetry of these nuclei likely contribute to and promote the basic functions of granulocytes. These features of the nuclei, especially the bilateral symmetry, may also shed light on the intranuclear order of chromosomes. A long-lasting debate on this issue was opened by Rabl [1] who stated, 'Ordnung muss sein' and later contradicted by Comings [2] who commented '... in mammals and humans ... no order is discernible'. Detailed studies of interphase cytogenetics by fluorescent in situ hybridization (FISH) protocols have revealed an intriguing order of the chromosomes in interphase and metaphase nuclei [3-11]. Furthermore, a 25-year study in developmental genetics has elucidated the mode and order of gene expression and has been described by Kmita and Duboule [12] as an activation of 'transcription factors in a precise temporal and spatial sequence that follows their chromosomal order'.

\section{KARGER \\ Fax +41613061234 E-Mail karger@karger.ch} www.karger.com
Jyoti P. Chaudhuri, MSc, PhD

LMU Kinderklinik

Lindwurmstrasse 4

DE-80337 Munich (Germany)

E-Mail JyotiChaudhuri@gmail.com 
Based on our observations, we shall discuss how segmentation, condensation and bilateral symmetry of granulocytic nuclei may support their immunologic efficiency, outline an apparent intranuclear order and establish a clear structure-function relationship.

\section{Materials and Methods}

We started these studies in the Tumor Cytogenetic Unit of the Pediatric Department of the Ludwig Maximillians University (LMU) of Munich (Germany) using both native smears and cytogenetic preparations from blood and bone marrow of about 350 specimens annually. Bone marrow and peripheral blood smears were fixed with ethanol-acetic acid (3:1) in a Coplin jar for $20 \mathrm{~min}$. Alternatively, the cells were washed and fixed in suspension and then air-dried on slides. For cytogenetic preparations, routine short-term cultures were used with and without cytokines (GM-CSF) in RPMI 1640 medium supplemented with $20 \%$ fetal bovine serum (Seromed, Berlin, Germany). Following colchicine and hypotonic treatments, the cells were harvested and fixed in suspension with ethanol-acetic acid (3:1) before being spread and air-dried on slides. Some specimens of blood and bone marrow were received as smears stained with Giemsa or Romanowsky, which were destained and dehydrated before applying FISH. Samples from blood and bone marrow and other sources like tissue sections in the diagnostic laboratories of Genedia GmbH (Munich, Germany) and Genzyme Genetics/ IMPATH (Phoenix, Ariz., USA) have supplemented these investigations.

FISH was done using centromeric and locus-specific DNA probes, which were directly labeled with the fluorophores spectrum orange, green, aqua and gold (Abbott-Vysis, Downers Grove, Ill., USA). The following probes were used: probe pairs CEP 3/7, $7 / 8,7 / 9,8 / 9,9 / 11, X / Y$, LSI $8 q / 21 q, 9 q / 22 q, 11 q / 14 q, 12 p / 21 q$ and $13 \mathrm{p} / 21 \mathrm{q}$; one tri-color probe $\mathrm{X} / \mathrm{Y} / 18$, and bi-color fusion probes ALK at HSA 2p23, BCL6 at HSA 3q27, MLL at HSA 11q, IGH at HSA $14 \mathrm{q} 32$ and MALT1 at HSA $18 \mathrm{q}$ as well as one tetra-color UroVysion probe complex representing HSA 3, 7, 9 and 17. Some specimens were stained sequentially using more than one probe combination or applying panels covering 5-11 different chromosomes. The probe and target DNAs were denatured simultaneously at $76^{\circ} \mathrm{C}$ for $2 \mathrm{~min}$ and then allowed to hybridize at $42^{\circ} \mathrm{C}$ for about $1 \mathrm{~h}$ and subsequently at $37^{\circ} \mathrm{C}$ for $4 \mathrm{~h}$ to overnight. After washing, cells were counterstained by mounting with a buffered medium containing 4',6-diamidino-2-phenylindole (DAPI) or by a short incubation in a dilute solution of DAPI before microscopic examination.

Microscopy and photomicrography were done using a Zeiss Axioskop ${ }^{\circledR}$ with triple band pass and other suitable filters for epifluorescence. Fuji color diapositive films were used for photographic documentations. Alternatively, an Olympus microscope with digital camera served for convenient capturing of cells with FISH signals. Routinely, we scanned 200-500 cell nuclei per specimen.

\section{Results}

Here we present our observations on human granulocytes from thousands of specimens of blood, bone marrow and other tissues mainly from cases of leukemia and lymphoma from Europe and the USA examined during the last 15 years at LMU and Genedia, and IMPATH and Genzyme Genetics.

Most of the granulocytes in the peripheral blood are neutrophil leukocytes, also known as PMN cells, a term that includes basophilic and eosinophilic leukocytes as well. Their nuclei are polymorphic on two accounts. First, they are segmented into two to five or more lobes. Secondly, nuclei of these highly differentiated cells may change their morphology by changing the form of the segments and by merging the adjacent segments or stretching them apart.

In many specimens, a sizeable proportion of granulocyte nuclei has an annular shape with or without segmentations.

A very prominent feature of these nuclei, annular or not, was their bilateral symmetry. This symmetry was often highlighted with symmetric distribution of the signals of chromosome-specific FISH probes (fig. 1). This kind of bilateral symmetry (based apparently on the two clusters formed by the two parental sets of chromosomes) was observed in all kinds of cell nuclei of blood and bone marrow - PMN or mononuclear cells in interphase as well as in cells at metaphase (fig. 2). In metaphases from short-term cultures, we observed clustering of the two sets of chromosomes in three different fashion styles: (1) the two parental sets lying side by side; (2) one parental set surrounds the other in a central compact cluster, and (3) the homologous chromosomes of the two parental sets tend to orient opposite to each other on metaphase spreads and metaphase plates (fig. 3-5). Another nuclear feature, observed in both mononuclear and PMN cells, highlights the phenomenon of separation of the two parental sets of chromosomes. Nuclei of these cells show typically a biphasic distribution of chromatin as if one set of chromosomal chromatin is condensed while the other is decondensed, perhaps in preparation for DNA replication or transcription (fig. 6a, b). An extreme form of biphasic distribution of chromatin, we observed, may be called a harlequin nucleus: with one set of chromosomes at metaphase and the other at interphase (fig. 6c, d).

However, the proportion of PMN nuclei with this symmetry feature was generally very high although variable from specimen to specimen (table 1). The bilateral 
Fig. 1. Bilaterally symmetric nuclei of granulocytes have equal quantity of DNA in each of their two halves with equitable distribution of chromosome-specific FISH signals, indicating the separation of maternal and paternal genomes $(\mathbf{a}-\mathbf{g})$. The nuclei are annular (b-d), tetraploid and annular (e) and annular but folded and may also take a bi-lobed (bi-segmented) form (f). The segmented nuclei of granulocytes are generally more condensed than the spheroid nuclei of so-called mononuclear cells (g). Hardly visible connections between lobes, too thin for DAPI, are visible on hybridization $(\mathbf{h}, \mathbf{i})$, here with red fluorochrome-labeled ABL sequence of probe for $\mathrm{t}(9 ; 22)$. PMN cells with such uneven segments may obviously be less efficient in locomotion.
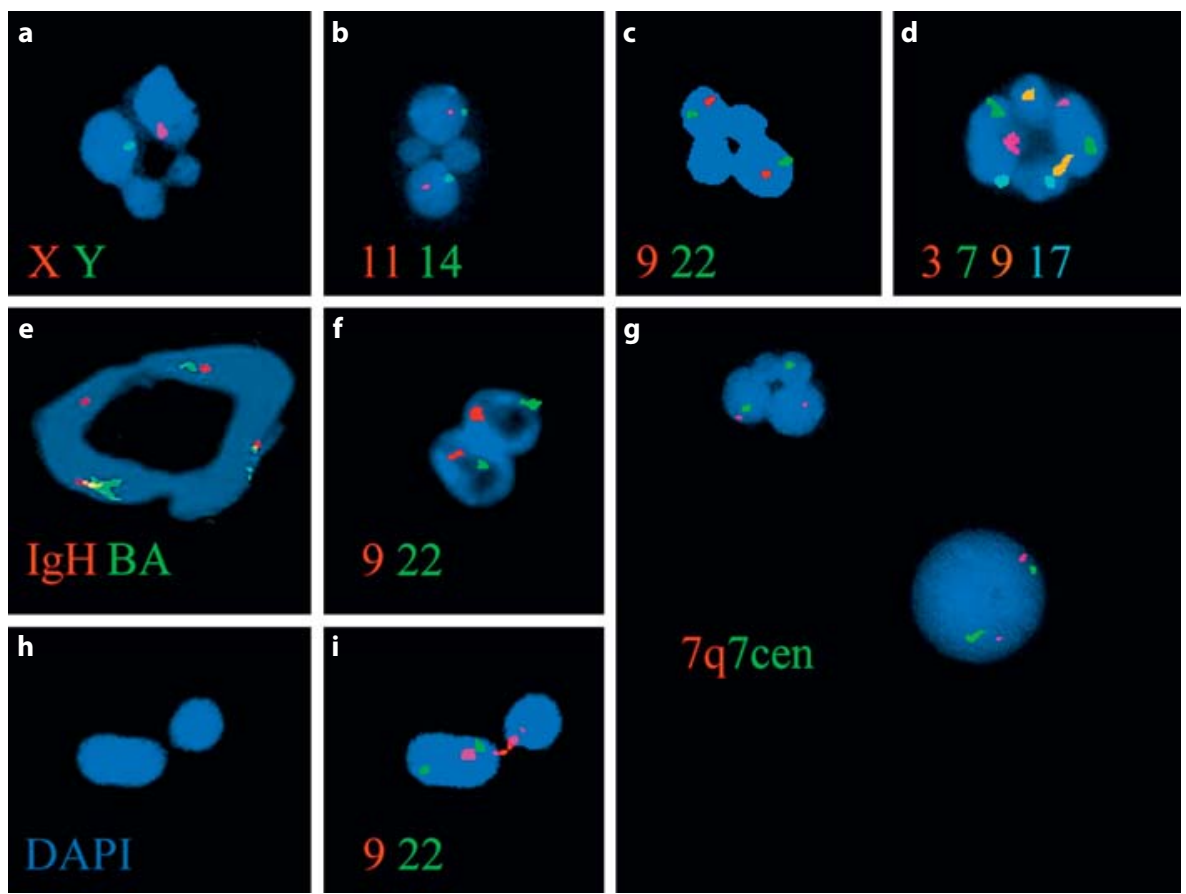

symmetry of the PMN nuclei was comparatively rare in specimens highly positive for leukemic chromosomal changes like BCR-ABL translocations (table 2).

\section{Discussion}

The formations of nuclear segments in PMN cells and the signal distribution of chromosome-specific FISH probes on them seems to contain a lot of information regarding the structure of the mammalian nuclei with important functional bearings.

\section{Nuclei of Neutrophils Achieve Segmentation}

After elaborate studies of dividing human fibroblasts by cinematography and by staining of fixed cells, Miles [13] indicated that the chromosomes become coated with lamin molecules at telophase and form a convoluted chain or ring comprised of all chromosomes. Inducing reversible chromosome condensation in a $\mathrm{CHO}$ cell line, Gacsi et al. [14] observed a linear arrangement of chromosomes by computer image analysis of the nuclei. Miles [13] had already observed that the chromosome chain folds to form a spherical nucleus.

The nuclei of normal human neutrophils may share an annular shape with several species, like rats and mice, as observed by Cabral and Robert [15]. Stavem et al. [16] re-
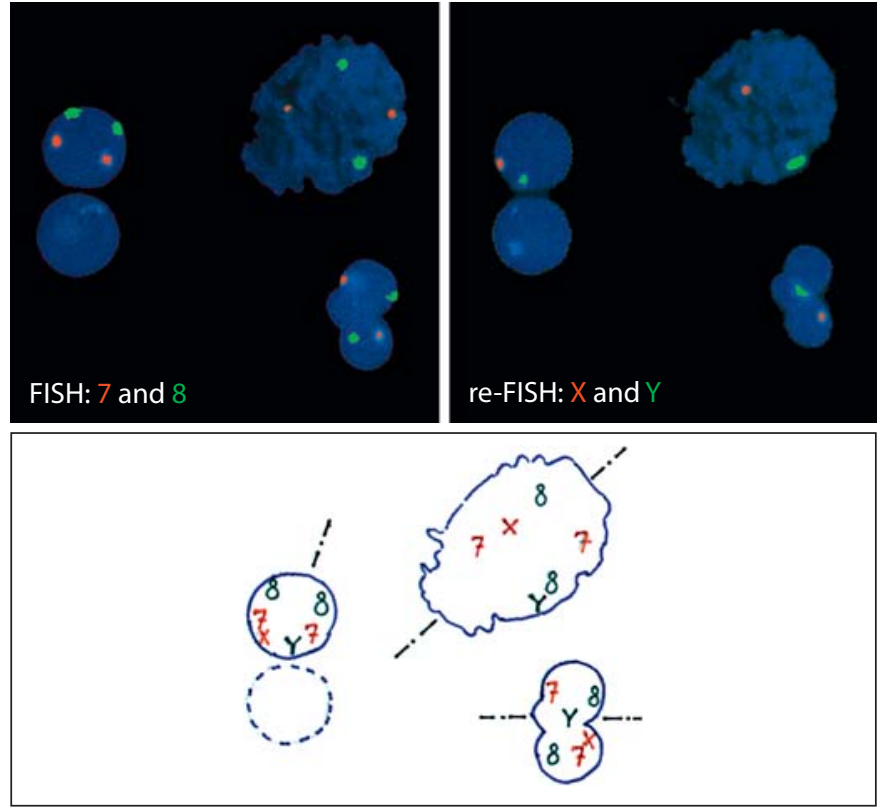

Fig. 2. Bilateral signal pattern in 3 cell nuclei - a mononuclear cell, a metaphase and a PMN nucleus with bilateral symmetry - from a short-term bone marrow culture (see Chaudhuri and Walther [8] for more images). 


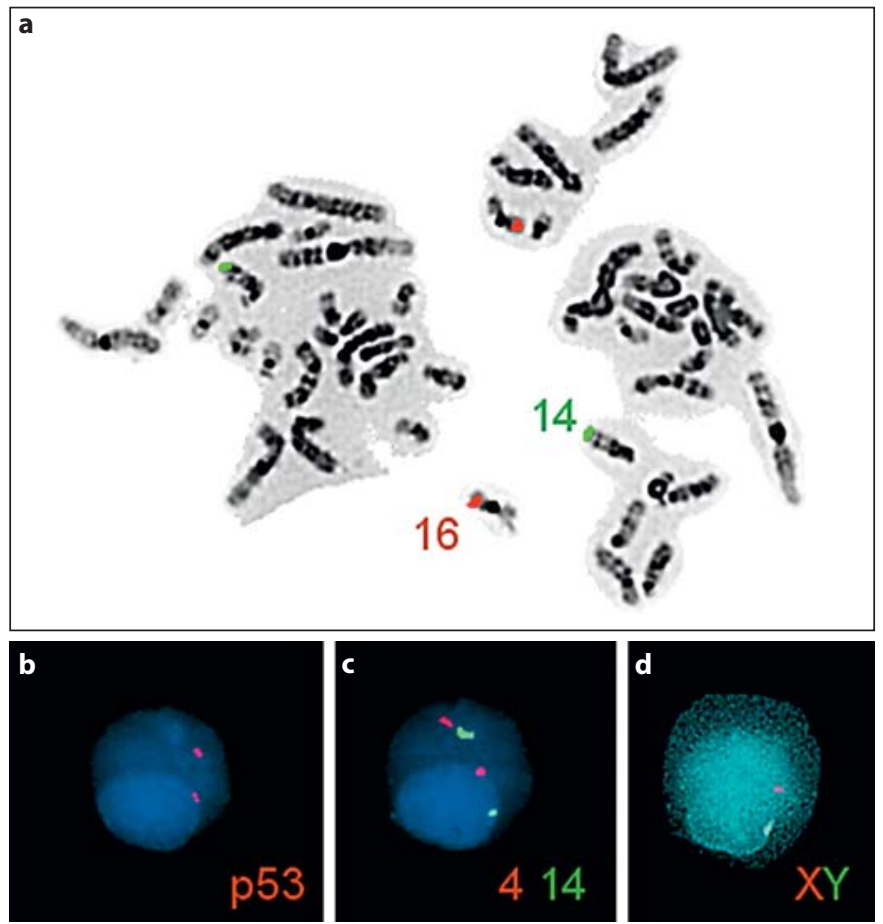

Fig. 3. A metaphase spread (a) and an interphase nucleus sequentially stained with three different probes $(\mathbf{b}-\mathbf{d})$ indicating lateral separation of the parental genomes.

ported on ring-shaped nuclei of human granulocytes in acute erythroleukemia. In some patients with myelodysplastic crisis, we have observed extended ring-like nuclei in about $80 \%$ of the myelocytes [8]. This phenomenon was also reported from different disorders of myelocytes [17].

Possibly, such a ring, when folded in the form of the figure eight, may give rise to a bi-segmented nucleus (fig. 1f). Alternatively, a chain of chromosomes forming a nucleus may appear as a band, which may fold by twisting and thereby form segments. Further folding may create a tri-, tetra- or penta-segmented nucleus (fig. 1a-d), or it may also unfold to reduce the number of segments. Commonly, the neutrophil leukocytes have three segments. The segments of such a nucleus are very often connected to each other forming a ring (fig. $1 \mathrm{~b}-\mathrm{d}$ ), at times with thin DNA bridges hardly visible under the light microscope (fig. 1h, i).

\section{Attributes of Neutrophils with Segmented and}

Condensed Nuclei

To patrol as scavengers through the different tissues, neutrophils leave the blood vessels creeping through the

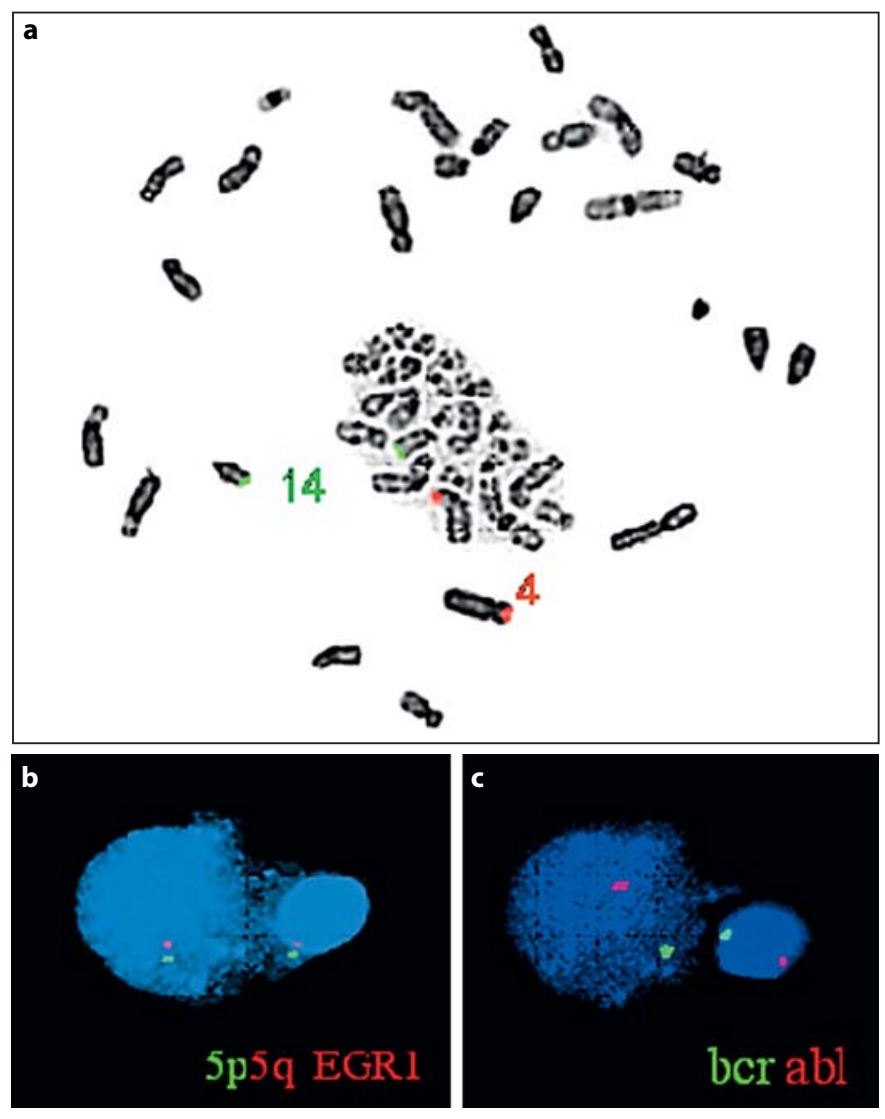

Fig. 4. A metaphase spread (above) and an interphase nucleus (below) with concentric separation of parental genomes: one set surrounds the other, a central mass of condensed chromosomes (a) or a central mass of condensed chromatin which has popped out (b, c).

capillary walls. Then, they squeeze themselves through the interstitial spaces to reach the focus of injury, invasion and inflammation [18]. This kind of transmigration is also supported by the pericytes of the venular wall, as observed in confocal intravital microscopy [19]. However, both escaping from blood vessels and the patrolling tissues by passage through intercellular matrix are facilitated by highly condensed and segmented nuclei (fig. 1e, 7: an image showing diapedesis and extravasal activities).

\section{Life Cycle of Neutrophils}

Myelocytes proliferate in bone marrow and differentiate into neutrophils, basophils and eosinophils. During maturation, they acquire cytoplasmic granules and undergo nuclear segmentation and condensation (cf. nuclei in fig. 1e). Within 3-5 days of maturation, the neutrophils leave the bone marrow and reach the blood stream. About 

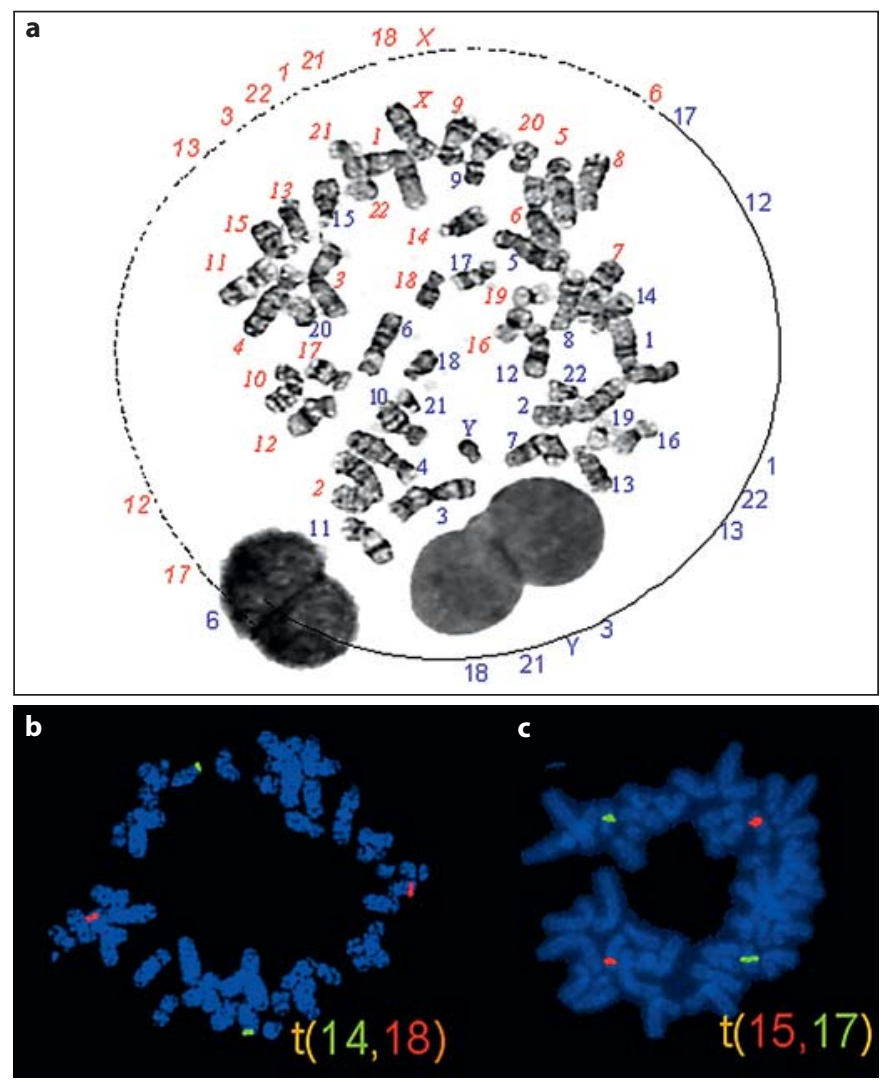

Fig. 5. Homologous chromosomes tend to orient opposite to each other: in a metaphase spread from a short-term blood culture (a) and in metaphase plates from a lymphoid cell line $(\mathbf{b}, \mathbf{c})$. Thus each metaphase has two groups of chromosomes, each apparently representing one set of chromosomes.

$70 \%$ of peripheral blood leukocytes in adults are granulocytes, the vast majority ( $>95 \%$ ) of them being neutrophils. Some may die in the bone marrow or blood and be eliminated by macrophages and phagocytes. Others leave the blood vessels and enter the extravasal space to scavenge peripheral tissues. Having completed their mission of patrolling, they ultimately reach the body surface (skin or mucous membrane) and die and are shed off along with dead or dying epithelial cells.

\section{Function of Neutrophils}

Neutrophils form the first line of defense, mounting an important aspect of our immune system. They detect and respond to invading foreign agents and pathogens. Smaller agents like microbes are ingested by neutrophils and digested with lysosomal enzymes from their cytoplasmic granules. Neutrophils, unlike lymphocytes, never return
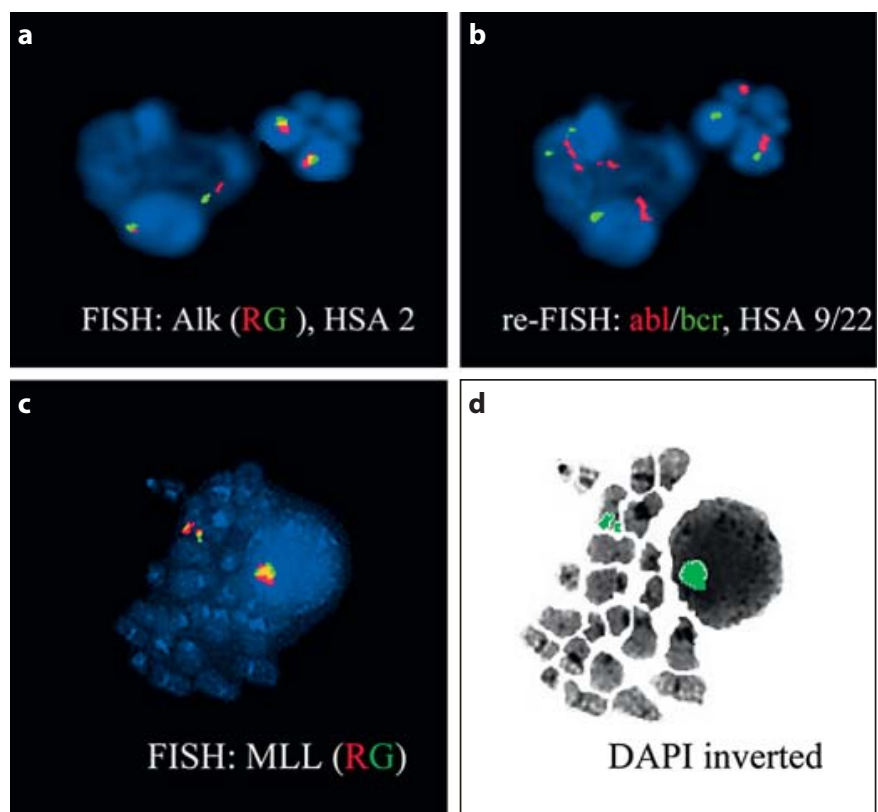

Fig. 6. A nucleus with biphasic chromatin condensation stained sequentially with dual-color probes Alk and abl/bcr, representing the chromosomes HSA 2, 9 and 22 (a, b). Signals are equitably distributed in the two chromatin areas, apparently representing the two parental genomes. Signals in the decondensed chromatin are elongated. (The accompanying nucleus of a granulocyte serves as a reference.) c, $\mathbf{d} \mathrm{A}$ harlequin nucleus of a bone marrow cell: one set of chromosomes at metaphase and the other at interphase, an extreme form of biphasic chromatin condensation. Such nuclei were described earlier as partial prematurely condensed chromosomes.

to the vascular system. Their constant and continuous oneway traffic is maintained by a high rate of proliferation and differentiation to support chemotaxis, an efficient mechanism of directed locomotion in response to cytokines.

\section{Segmented Nuclei of Neutrophils Show Bilateral \\ Symmetry}

In a previous study, we analyzed hundreds of neutrophils using image cytometry of chromatin patterns and DNA distribution in their nuclei applying the Feulgen reaction using the protocol of Papadimitriou and Shellam [20]. For further algorithmic processing, we scanned the captured images two more times. Thereby, examining them sequentially two more times, it appeared that these segmented nuclei often had bilateral symmetry. DNA measurement of both halves of these nuclei stained by the Feulgen reaction gave exactly the same value in each half 
Fig. 7. Diagram of a neutrophil leukocyte with a bilaterally symmetric trilobed (trisegmented) nucleus illustrating: (1) how the nuclear segmentation facilitates diapedesis and (2) how the nuclear symmetry axis coincides with the axis of polarity and the direction of locomotion of the cell in the extravasal phase (source: www.chronicprostatitis.com/images/f3.jpg).

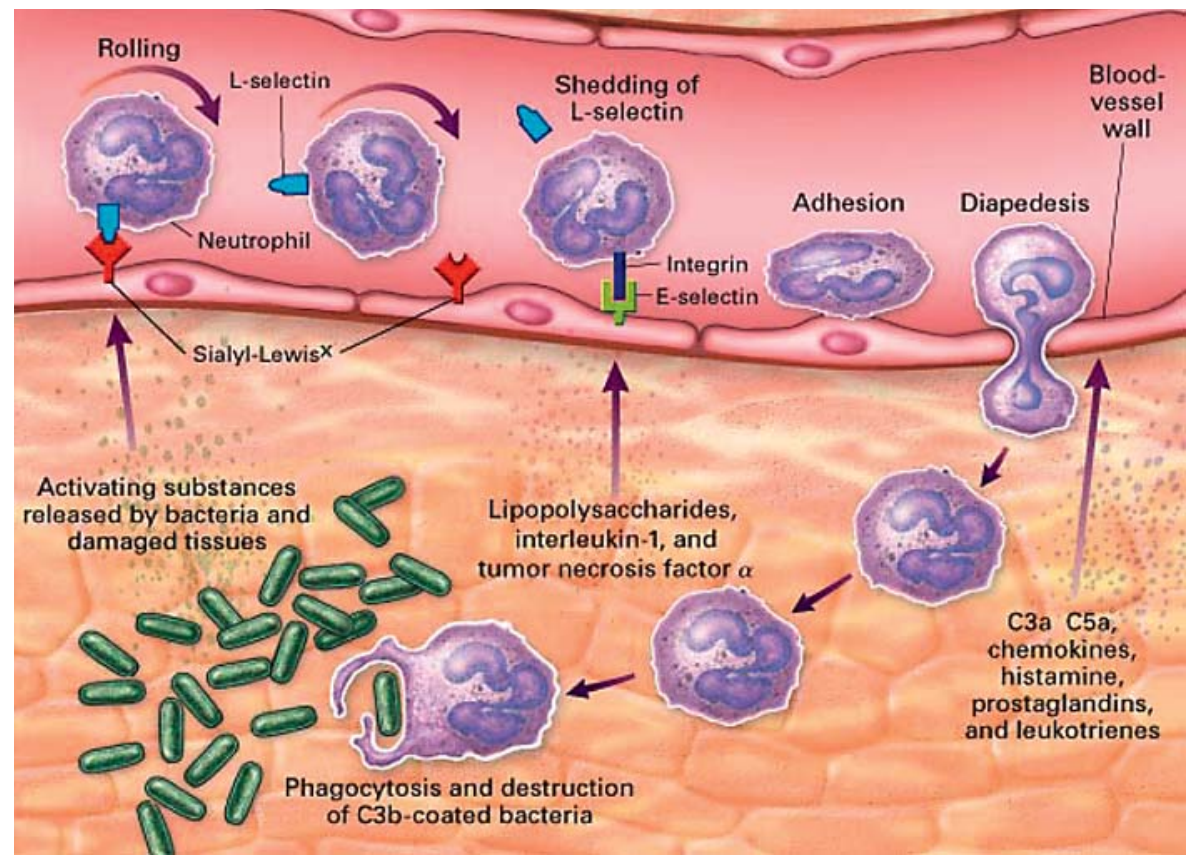

Table 1. Distribution pattern of dual signals generated by AbbottVysis probes representing two different chromosomes [PMLRARA, t(15;17), ETO-AML1, t(12;21), CEP 2 and 8, or X and Y] in bi-lobed or bilaterally symmetric segmented nuclei from human blood or bone marrow ( 30 cells from each of the 6 chromosomally normal cases)

\begin{tabular}{llrrrr}
\hline $\begin{array}{l}\text { Case } \\
\text { No. }\end{array}$ & Probes & $\begin{array}{l}\text { Bilateral } \\
\text { pattern }\end{array}$ & $\begin{array}{l}\text { Dubious } \\
\text { pattern }\end{array}$ & $\begin{array}{l}\text { Non-bilat- } \\
\text { eral pattern }\end{array}$ & $\begin{array}{l}\text { Nuclei } \\
\text { total }\end{array}$ \\
\hline 1 & PML-RARA & $13(43.3 \%)$ & 3 & 14 & 30 \\
2 & PML-RARA & $12(40.0 \%)$ & 7 & 11 & 30 \\
3 & ETO-AML1 & $9(30.0 \%)$ & 13 & 8 & 30 \\
4 & ETO-AML1 & $14(46.7 \%)$ & 9 & 7 & 30 \\
5 & CEP 2 and 8 & $14(46.7 \%)$ & 7 & 9 & 30 \\
6 & X and Y & $19(63.3 \%)$ & 4 & 7 & 30 \\
\hline
\end{tabular}

Table 2. Distribution pattern of ABL and BCR signals generated by Abbott-Vysis probes for translocation BCR-ABL, $t(9 ; 22)$, in bilobed or bilaterally symmetric segmented nuclei from human blood or bone marrow (5 randomly chosen fields from each case)

\begin{tabular}{llllll}
\hline $\begin{array}{l}\text { Case } \\
\text { No. }\end{array}$ & $\begin{array}{l}\text { Translocation } \\
\text { BCR-ABL }\end{array}$ & $\begin{array}{l}\text { Bilateral } \\
\text { pattern }\end{array}$ & $\begin{array}{l}\text { Dubious } \\
\text { pattern }\end{array}$ & $\begin{array}{l}\text { Non-bilat- } \\
\text { eral pattern }\end{array}$ & $\begin{array}{l}\text { Nuclei } \\
\text { total }\end{array}$ \\
\hline 1 & Negative & $19(76.0 \%)$ & 2 & 4 & 25 \\
2 & Positive & $9(52.9 \%)$ & 1 & 7 & 17 \\
3 & Positive & $9(50.0 \%)$ & 3 & 6 & 18 \\
4 & Positive & $8(33.3 \%)$ & 6 & 7 & 21 \\
5 & Positive & $10(42.0 \%)$ & 5 & 9 & 24 \\
\hline
\end{tabular}

of a nucleus with bilateral symmetry [3]. Subsequent tests with a number of chromosome-specific centromeric FISH signals suggested that their intranuclear distribution represents segregation of the homologous chromosomes into two groups highlighting the bilateral symmetry $[3,21]$ (fig. 1a-g). These observations indicated that each half of a bilaterally symmetric nucleus represents one of the two parental sets of chromosomes [3, 8-10,21]. Numerous other studies on epithelial and hematological cells support this distribution pattern, e.g., Koss [22], Nagele et al. [4] and Bartova et al. [5].

\section{Functional Contribution of Bilateral Symmetry of the Nuclei}

Neutrophils are possibly the most efficient cells in locomotion. Over $90 \%$ of the leukocytes reaching a site of inflammation within $1 \mathrm{~h}$ of an insult causing an Arthustype reaction are neutrophils. These leukocytes most likely are the fastest moving cells, attaining up to $30 \mu \mathrm{m} /$ min in vitro [23].

Cytokines induce the directional movement of these PMN cells by providing the guiding signals [24], but their efficiency in locomotion is enhanced by their special nuclear morphology. Cells with segmented nuclei having a high degree of compaction may pass through the intercellular junctions of endothelium of blood vessels and through extravascular tissue more easily. Nuclear segmentation, compaction and bilateral symmetry along 
Fig. 8. Diagram of a PMN leukocyte at three stages of its amoeboid locomotion. The orientation of the nucleus (blue) and its axis of bilateral symmetry coincide with the axis of polarity of the cell and its direction of locomotion. Each of the two centrioles (green) of a diploid cell controls one half of the nucleus containing probably one of the two haploid sets of chromosomes. The centrioles connected with microtubules to the nuclear lobes move in harmony with the extension and retraction cycles of the anterior pseudopodia (lamellipod) and posterior uropod [based on ref. $3,8,23,25,27,29,30]$.

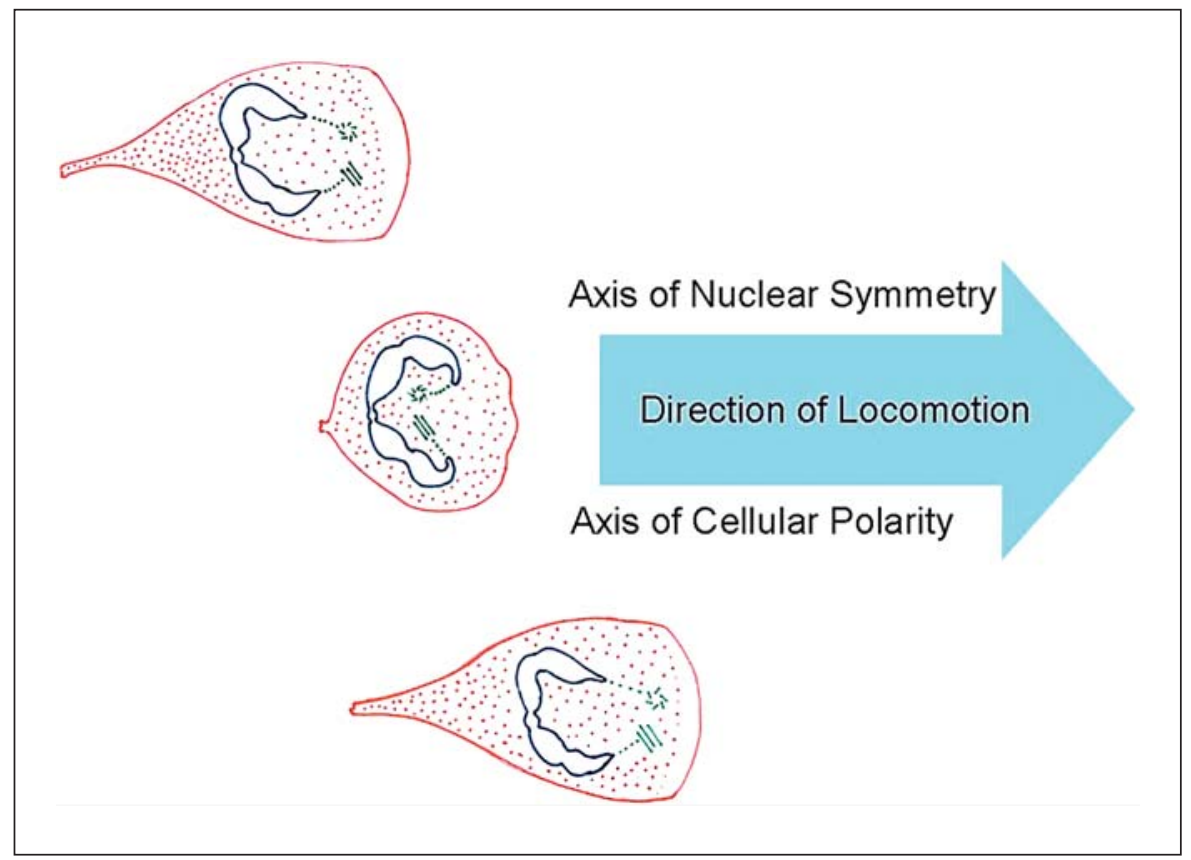

with the centrioles connected to the nuclear chromatin mass by microtubules may also serve as an internal cy toskeleton and support their efficient and directional amoeboid locomotion. These coordinated activities have been analyzed by time-lapse cinematography or video imaging plus electron or light microscopy with phase contrast and fluorescent optics [25-27]. The axis of polarity of a granulocyte during amoeboid locomotion on a substrate coincides with the axis of bilateral symmetry of its nucleus, as shown in figures 7 and 8 . Video frames (e.g. Malawista and de Boisfleury Chevance [28]), the diagrams reported by Fukushima et al. [29] and Bessis and Breton-Gorius [30] as well as in website www.chronicprostatitis.com/ images/f3.jpg and phase contrast microscopy [31] provide confirming evidence. Moreover, it is a common experience that anything capable of efficient locomotion possesses generally a basic bilateral symmetry (e.g. a car, a bike, a bird or a cat).

Immunologically, healthy individuals may therefore have a higher proportion of PMN leukocytes capable of attaining bilateral nuclear symmetry. Vice versa, the amoeboid locomotion of granulocytes is affected in leukemia, for example, by oncogene BCR-ABL, which is known to interfere with cytoskeletal components like microtubules connecting nuclear chromatin to cytoplasmic centriole [32-36] (table 2).

In cases of severe and prolonged infections, eosinophils are called into action. These cells are not only heav- ily laden with larger lysosomal granules, but they also almost always have perfectly balanced bi-segmented nuclei. These bilaterally symmetric nuclei may enhance a time-efficient locomotion to reach the site of a crisis. Fukushima et al. [29] recorded that the eosinophils were faster in chemotaxis than the neutrophils.

\section{Summary: Intranuclear Order of Bilateral \\ Symmetry Supports Chemotaxis}

Being bilaterally symmetric, having equitable distribution of DNA and a correspondingly equitable pattern of chromosome-specific FISH signals, the nuclei of these PMN leukocytes reveal a special order of nuclear architecture $[3,5]$, an aspect that might remain undetected in non-segmented and spheroid nuclei of the so-called mononuclear cells (as opposed to PMN cells).

These observations indicate that in diploid cells the two parental sets of chromosomes correspond to two distinct units of structure and function. Analysis of early embryogenesis revealed that the number of centrioles equals exactly the number of haploid sets of chromosomes in a cell [37]. (The second centriole of a spermatozoon is the originator and regulator of the flagellum, serving as tail, and is in no way connected to chromosomes or to the nuclear chromatin.) Cinematographic analysis of fibroblasts in mitotic cycles indicated that the chromosomal mass and the centrioles (centrosome), which are connected by microtubules as spindle fibers, 
together form a structure present permanently through the cell cycle [38]. Electron microscopy supported this view $[25,30,39]$. Each of the two masses of chromatin of a bi-segmented nucleus, representing possibly the two haploid sets of chromosomes, appears obviously to be bound by microtubules to one of the two centrioles of a diploid cell $[3,8,25,30]$. Rhythmic contractions and relaxations of those tubules anchored to each half of the segmented, compact and bilaterally symmetric nuclei of a granulocyte, as recorded by Bessis [25], contribute to its efficient and directional locomotion (fig. 8).

Perfect bilateral symmetry may be expected if the two symmetric halves of a nucleus represent the two parental genomes, each containing 23 chromosomes, as earlier presumed by us [3] and subsequently supported by others by similar observations in different human and murine cells $[4,5,7,22]$. Separation of the two parental genomes into two exclusive groups was also reported by others:

- analyzing ultrathin sections and applying differential in situ suppression hybridization of the two parental sets of chromosomes in monocot plants [40,41],

- in male scale insects (mealy bugs) with paternal chromosomes heterochromatic and condensed all through the cell cycle $[42,43]$,

- in rat liver cells using oxyquinoline banding techniques $[44,45]$,

- in preimplantation embryos of mice following impregnation by spermatozoa completely labeled with bromodeoxyuridine [46, 47], and

- in dicot hybrid plants using three-dimensional (3-D) FISH probed with species-specific centromere repeats [11].

Applying the same technique and similar 3-D analysis, Hepperger et al. [48] failed to find symmetric distribution of FISH signals in bi-lobed nuclei of human granulocytes in a total of 3 specimens. Perhaps this failure was due to the small number of cases and the very low proportion of them with cells with bilateral symmetry, or these specimens were from cases with immunologic deficiency. Similarly, Yerle-Bouissoin et al. [49] applied 3-D FISH on porcine neutrophils. However, they focused on the effect of lipopolysaccharide stimulation and did not examine the bilaterally symmetric nuclei.

Pera [50], while examining polyploidization with time lapse cinematography, followed a hexaploid cell of a vole (Microtus agrestis) up to the metaphase stage, where six haploid sets of chromosomes were seen lying distinctly separated in exclusive zones. Similar ploidy-wise distribution has also been reported in tetraploid cells of human blood and bone marrow [8] and in polyploid dicot plants Torenia [11].

Observations of the loss of maternal chromosome 11 $[51,52]$ and especially the genome-wide loss of maternal alleles in Wilms' tumors [53], ploidy-wise distribution of chromosomes in a polyploid cell line documented by Pera [50], behavior of the haploid units during gametogenesis in a bisexually reproducing all triploid vertebrate [54] and biphasic distributions of chromatin condensations in blood and bone marrow cells [9] suggest that chromosomes are handled and/or addressed ploidy-wise, i.e. genome-wise, so that maternal and paternal genomes may also act alternately by opportunity or availability or necessity (cf. a mixed double tennis match). By necessity, the parental genomes do also participate in harmonious cooperation, when the chromosomes bearing nucleolus-organizing regions come together to build a nucleolus, for example, although they are tethered to their respective centrioles (see online supplementary fig. 9-12 at www. karger.com/doi/10.1159/000343037).

\section{Conclusion}

These findings indicate two important aspects of the intranuclear order:

(1) the two parental sets of chromosomes form the two genomic units of a diploid nucleus, and

(2) in a bilaterally symmetric nucleus of a PMN leukocyte each of the two genomes, i.e. each of the two halves of the nuclei, with its own centriole may determine the axis of locomotion of a bipolar granulocyte and thereby support an efficient chemotaxis.

\section{Acknowledgments}

An essential part of this work was generously supported by a research grant from the Wilhelm-Sander-Stiftung, Munich (grant No. 97.080.1 Molekular Cytogenetik). The authors are also thankful to the experts of Genzyme Genetics: Drs. Eduardo Cantu and John McGill for valuable suggestions and Dr. Sultan Karamanov and Ms. Liliana Scott-Durand for qualified assistance. We thankfully acknowledge additional technical support from Drs. Anja Weise and Samarth Bhatt (Institute of Human Genetics, Medical Faculty, Jena University, Jena, Germany). 


\section{References}

1 Rabl C: Ueber die Zelltheilung. Morpholo- 17 Olins AL, Olins DE: The mechanism of grangisches Jahrbuch 1885;10:214-330.

$\checkmark 2$ Comings DE: Arrangement of chromatin in the nucleus. Hum Genet 1980;53:131-143.

3 Chaudhuri JP, Reith A: Symmetric chromosomal order in leukocytes indicated by DNA image cytometry and fluorescence in situ hybridization. Analyt Quant Cytol Histol 1997; 19:30-36.

4 Nagele RG, Freeman T, McMorrow L, Thomson Z, Kitson-Wind K, Lee H: Chromosomes exhibit preferential positioning in nuclei of quiescent human cells. J Cell Sci 1999;112: 525-535.

-5 Bartova E, Kozubek S, Jirsova P, Kozubek M, Lukasova E, Skalnikova M, Cafourkova A, Koutna I, Pasekova R: Higher-order chromatin structure of human granulocytes. Chromosoma 2001;110:360-370.

6 Parada LA, Misteli T: Chromosome positioning in the interphase nucleus. Trends Cell Biol 2002;12:425-432.

7 Parada LA, McQueen PG, Munson PJ, Misteli T: Conservation of relative chromosome positioning in normal and cancer cells. Curr Biol 2002;12:1692-1697.

$\checkmark 8$ Chaudhuri JP, Walther JU: Separation of parental genomes in human blood and bone marrow cells and its implications. Int J Oncol 2003;23:1257-1262.

\9 Chaudhuri JP, Kasprzycki E, Battaglia M, McGill JR, Brøgger A, Walther JU, Reith A: Biphasic chromatin structure and FISH signals reflect intranuclear order. Cell Oncol 2005;27:327-334.

10 Chaudhuri JP, Karamanov S, Paulraj P, McGill JR, Walther JU: Identification of parental chromosomes involved in translocations BCR-ABL, t $(9 ; 22)$ and PML-RARA, $t(15 ; 17)$. Anticancer Res 2008;28:3573-3578.

11 Kikuchi S, Tanaka H, Wako T, Tsujimoto H: Centromere separation and association in the nuclei of an interspecific hybrid between Torenia fournieri and T. baillnii (Scrophulariaceae) during mitosis and meiosis. Genes Genet Syst 2007;82:369-375.

12 Kmita M, Duboule D: Organizing axes in time and space; 25 years of collinear tinkering. Science 2003;301:331-333.

13 Miles CP: Chromatin elements and nuclear morphology in human mitosis. Acta Cytol 1964;8:356-367.

14 Gacsi M, Nagy G, Pinter G, Basnakian AG, Banfalvi G: Condensation of interphase chromatin in nuclei of synchronized Chinese hamster ovary (CHO-K1) cells. DNA Cell Biol 2005;24:43-53.

15 Cabral HR, Robert GB: Ring-shaped nuclei in human neutrophylic leukocytes of healthy individuals: evidence of their occurrence and characteristics. Am J Haematol 1989;30: 259-260.

- 16 Stavem P, Hjort PF, Vogt E, van der Hagen $\mathrm{CB}$ : Ring-shaped nuclei of granulocytes in a patient with acute erythroleukaemia. Scand J Haematol 1969;6:31. ulocyte nuclear shape determination: possible involvement of the centrosome. Eur J Cell Biol 2005;84:181-188.

18 Muller WA: Leukocyte-endothelial cell interactions in the inflammatory response. Lab Invest 2002;82:521-533.

19 Proebstl D, Voisin MB, Woodfin A, Whiteford J, D'Acquisto F, Jones GE, Rowe D, Noursharg S: Pericytes support neutrophil subendothelial cell crawling and breaching of venular walls in vivo. J Exp Med 2012;209: 1219-1234.

20 Papadimitriou JM, Shellam GR: A cytophotometric measurement of DNA in murine hepatocytic nuclei during cytomegalovirus infection. Histochemistry 1981;72:481-487.

21 Chaudhuri JP, Fringes B, Reith A: Topographic order of chromosomes in leukocytes indicated by DNA image cytometry and mono or dual colour FISH with five different probes. Verh Dtsch Ges Pathol 1997;81:689.

22 Koss LG: Characteristics of chromosomes in polarized normal human bronchial cells provide a blue print for nuclear organization. Cytogenet Cell Genet 1998;82:230-237.

23 Zigmond SH: Recent quantitative studies of actin filament turnover during cell locomotion. Cell Motil Cytoskel 1993;25:309-316.

24 Parent CA: Making all the right moves: chemotaxis in neutrophils and Dictyostelium Curr Opin Cell Biol 2004;16:4-13.

25 Bessis M: Living Blood Cells and Their Ultrastructure. Berlin, Springer, 1973, pp 319320, fig 251-252.

26 Naik NR, Advani SH, Bhisey AN: PMN cells from chronic myeloid leukemia (CML) patients show defective chemotaxis in remission. Leuk Res 1989;13:959-965.

27 Malawista SE, de Boisfleury Chevance A, Boxer LA: Random locomotion and chemotaxis of human blood polymorphonuclear leukocytes from a patient with leukocyte adhesion deficiency-1: normal displacement in close quarters via chimneying. Cell Motil Cytoskeleton 2000;46:183-189.

28 Malawista SE, de Boisfleury Chevance A: Cytokineplast: purified, stable and functional motile machinery from human blood polymorphonuclear leukocytes. J Cell Biol 1982;95:960-973 (video frames $j-1$ on $p$ 963).

29 Fukushima K, Senda N, Miura H, Ishagami S, Murakami Y: Dynamic pattern in the movement of leukocytes I and II. Med J Osaka Univ 1954;5:1-46 and 47-56.

30 Bessis M, Breton-Gorius J: Rapports entre noyau et centrioles dans les granulocytes étalés. Role de microtubules. Nouv Rev Fr Hematol 1967;7:601-620.

31 Senda N, Tamura H, Shibata N, Yoshitake J, Kondo K, Tanaka K: The mechanism of the movement of leukocytes. Exp Cell Res 1975; 91:393-407.
32 Salgia R, Quackenbush E, Lin J, Souchkova N, Sattler M, Ewaniuk DS, Klucher KM, Daley GQ, Kraeft SK, Sackstein R, Alyea EP, von Andrian UH, Chen LB, Gutierrez-Ramos JC, Pendergast AM, Griffin JD: The BCR/ABL oncogene alters the chemotactic response to stromal-derived factor-1alpha. Blood 1999; 94:4233-4246

33 Geay JF, Buet D, Zhang Y, Foudi A, Jarrier P, Berthebaud M, Turhan AG, Vainchenker W, Louache F: p210BCR-ABL inhibits SDF-1 chemotactic response via alteration of CXCR4 signaling and down-regulation of CXCR4 expression. Cancer Res 2005;65:2676-2683.

34 Lavastre V, Chiasson S, Cavalli H, Girard D: Viscum album agglutinin-I induces apoptosis and degradation of cytoskeletal proteins via caspases in human leukaemia eosinophil AML14.3D10 cells: differences with purified human eosinophils. Br J Haematol 2005; 130 : 527-535.

35 Pierce A, Lu Y, Hamzah HG, Thompson S, Owen-Lynch PJ, Whetton AD, Spooncer E: Differential effect of leukaemogenic tyrosine kinases on cell motility is governed by subcellular localisation. Br J Haematol 2006;133: 345-352.

- 36 Patel H, Gordon MY: Abnormal centrosome-centriole cycle in chronic myeloid leukaemia? Br J Haematol 2009;146:408-417.

- 37 Krioutchkova MM, Onishchenko GE: Structural and functional characteristics of the centrosome in gametogenesis and early embryogenesis of animals. Int Rev Cytol 1999; 185:107-156

38 Lettré M, Lettré R: Un problem cytologique: la persistence des structures du fuseau dans l'intervalle des mitoses. Rev Hématol 1958; 13:337-365.

39 Fawcett DW: An Atlas of Fine Structure. The Cell. Philadelphia, Saunders, 1966, pp 60-62.

40 Bennett MD: Towards a general model for spatial law and order in nuclear and karyotypic architecture. Chromosomes Today 1984;8:190-202.

-41 Leitch AR, Schwarzacher T, Mossgöller W, Bennett MD, Helsop-Harrison JS: Parental genomes separated throughout the cell cycle in plant hybrid. Chromosoma 1991;101:206-213.

42 Hughes-Schrader S: Cytology of coccids (Coccoïdea-Homoptera). Adv Genet 1948;2: 127-203.

43 Brown SW, Nur U: Heterochromatic chromosomes in the coccids. Science 1964;145: 130-136.

44 Gläss E: Die Identifizierung der Chromosomen im Karyotyp der Rattenleber. Chromosoma 1956;7:655-669.

45 Gläss E: Sonderung der ChromosomenSätze in Rattenleberzellen. Chromosoma 1957;8:468-492.

-46 Mayer W, Niveleau A, Walter J, Fundele R, Haaf T: Demethylation of the zygotic paternal genome. Nature 2000;403:501-502. 
-47 Mayer W, Smith A, Fundele R, Haaf T: Spatial separation of parental genomes in preimplantation mouse embryos. J Cell Biol 2000; 148:629-634.

-48 Hepperger C, Mayer A, Merz J, Vanderwall DK, Dietzel S: Parental genomes mix in mule and human cell nucleus. Chromosoma 2009; 118:335-347.

-49 Yerle-Bouissoin M, Mompart F, Iannuccelli E, Robelin D, Jauneau A, Lahbib-Mansais Y, Delcros C, Oswald IP, Gellin J: Nuclear architecture of resting and LPS-stimulated porcine neutrophils by 3D FISH. Chromosome Res 2009; 17:847-862.

50 Pera F: Mechanismen der Polyploidisierung und der somatischen Reduktion. Berlin, Springer, 1970, p 50.

51 Schroeder Wanda T, Chao LY, Dao DD, Strong LC, Pathak S, Riccardi V, Lewis WH, Saunders GF: Nonrandom loss of maternal chromosome 11 alleles in Wilms tumors. Am J Hum Genet 1987;40:413-420.
52 Cerrato F, Sparago A, Verde G, De Crescenzo A, Citro V, Cubellis MV, Rinaldi MM, Boccuto L, Neri G, Magnani C, D’Angelo P, Collini P, Perotti D, Sebastio G, Maher ER, Riccio A: Different mechanisms cause imprinting defects at the IGF2/H19 locus in Beckwith-Wiedemann syndrome and Wilms tumour. Hum Mol Genet 2008; 17: 1427-1435.

53 Hoban PR, Heighway J, White GRM, Baker B, Gardner J, Birch JM, Morris-Jones P, Kelsey AM: Genome-wide loss of maternal alleles in a nephrogenic rest and Wilms' tumor from a BWS patient. Hum Genet 1995;95:651-656.

54 Stöck M, Lamatsch DK, Steinlein DK, Epplen JT, Grosse WR, Hock R, Klappenstück T, Lampert KP, Scheer U, Schmid M, Schartl M: A bisexually reproducing all-triploid vertebrate. Nat Genet 2002;30:325-328.

\section{Note Added in Proof}

Studies applying the parental-origindetermination FISH [1] on lymphoid cell line trios in collaboration with the team of Dr. Anja Weise in the Institute of Human Genetics at Jena University and supported by Carl Zeiss MicroImaging GmbH revealed that the most of the 170 metaphases tested so far were positive for the intranuclear separation of the maternal and paternal chromosome sets, as indicated in this work.

\section{Reference}

Weise A, Gross M, Mrasek K, Mkrtchyan $\mathrm{H}$, Horsthemke B, Jonsrud C, Von Eggeling F, Hinreiner S, Witthuhn V, Claussen U, Liehr T: Parental-origin-determination fluorescence in situ hybridization distinguishes homologous human chromosomes on single-cell level. Int J Mol Med 2008;21:189200. 